\title{
Branching projections of ventrolateral reticular neurons to the medial preoptic area and lumbo-sacral spinal cord
} Antonella Russo*1, Rosalia Pellitteri ${ }^{2}$, Rosa Romeo ${ }^{3}$, Stefania Stanzani ${ }^{1}$ and André Jean ${ }^{4}$

\begin{abstract}
Address: ${ }^{1}$ Department of Physiological Sciences, University of Catania, Catania, Italy, ${ }^{2}$ Institute of Neurological Science, Research National Council, Catania, Italy, ${ }^{3}$ Department of Anatomy, Diagnostic Pathology, Phorens Medicine, Hygiene and Public Health, University of Catania, Catania, Italy and ${ }^{4}$ Laboratoire de Physiologie Neurovégétative, UMR 6153-CNRS 1147-INRA, Université Aix-Marseille III, Faculté des Sciences St. Jerôme, Marseille, France
\end{abstract}

Email: Antonella Russo* - antrusso@unict.it; Rosalia Pellitteri - r.pellitteri@isn.cnr.it; Rosa Romeo - romeros@unict.it; Stefania Stanzani - stanzani@unict.it; André Jean - andre.jean@univ.u-3mrs.fr

* Corresponding author

Published: 07 October 2005

Behavioral and Brain Functions 2005, I:17 doi:10.1186/1744-908I-1-17
Received: 24 June 2005

Accepted: 07 October 2005

This article is available from: http://www.behavioralandbrainfunctions.com/content/I/I/I7

(c) 2005 Russo et al; licensee BioMed Central Ltd.

This is an Open Access article distributed under the terms of the Creative Commons Attribution License (http://creativecommons.org/licenses/by/2.0), which permits unrestricted use, distribution, and reproduction in any medium, provided the original work is properly cited.

\begin{abstract}
Different findings indicate that rostral ventrolateral reticular nucleus (RVL) is neuronal substrate of integration and regulation of the cardiovascular functions. Some efferent RVL neurons project to the thoraco-lumbar spinal cord and excite preganglionic sympathetic neurons, to the spinal phrenic motor neurons involved in inspiratory function and increase the activity of vasoconstrictor fibres innervating blood vessels in the skin and skeletal muscle. Our study was aimed at revealing presence of neurons within RVL supplying branching collateral input to the medial preoptic area (MPA) and to the lumbo-sacral spinal cord (SC-L) in the rat. All animal experiments were carried out in accordance with current institutional guidelines for the care and use of experimental animals. We have employed double fluorescent-labelling procedure: the projections were defined by injections of two retrograde tracers: Rhodamine Labelled Bead (RBL) and Fluoro Gold (FG) in the MPA and $S C-L$, respectively. Our results showed the presence of few single FG neurons and single RBL neurons in the RVL. The size of FG-neurons and RBL-neurons was medium $(25-30 \mu \mathrm{m})$ and large $(50 \mu \mathrm{m})$.

Few double-projecting neurons were distributed in the middle third of RVL nucleus, their size was $30-40 \mu \mathrm{m}$. The results demonstrate that pools of neurons in the RVL have collateral projections to the MPA and SC-L and they are involved in ascending and descending pathway. These data suggest that these neurons could play a role in maintaining activity of central and peripheral blood flow.
\end{abstract}

\section{Introduction}

Several findings indicate that rostral ventrolateral reticular medulla (RVL) is the fundamental neuronal substrate of the regulation of circulation and cardiovascular functions, that mediates vasomotor reflexes [1,2]. Different methods permitted to identify afferent projections to RVL, from the 

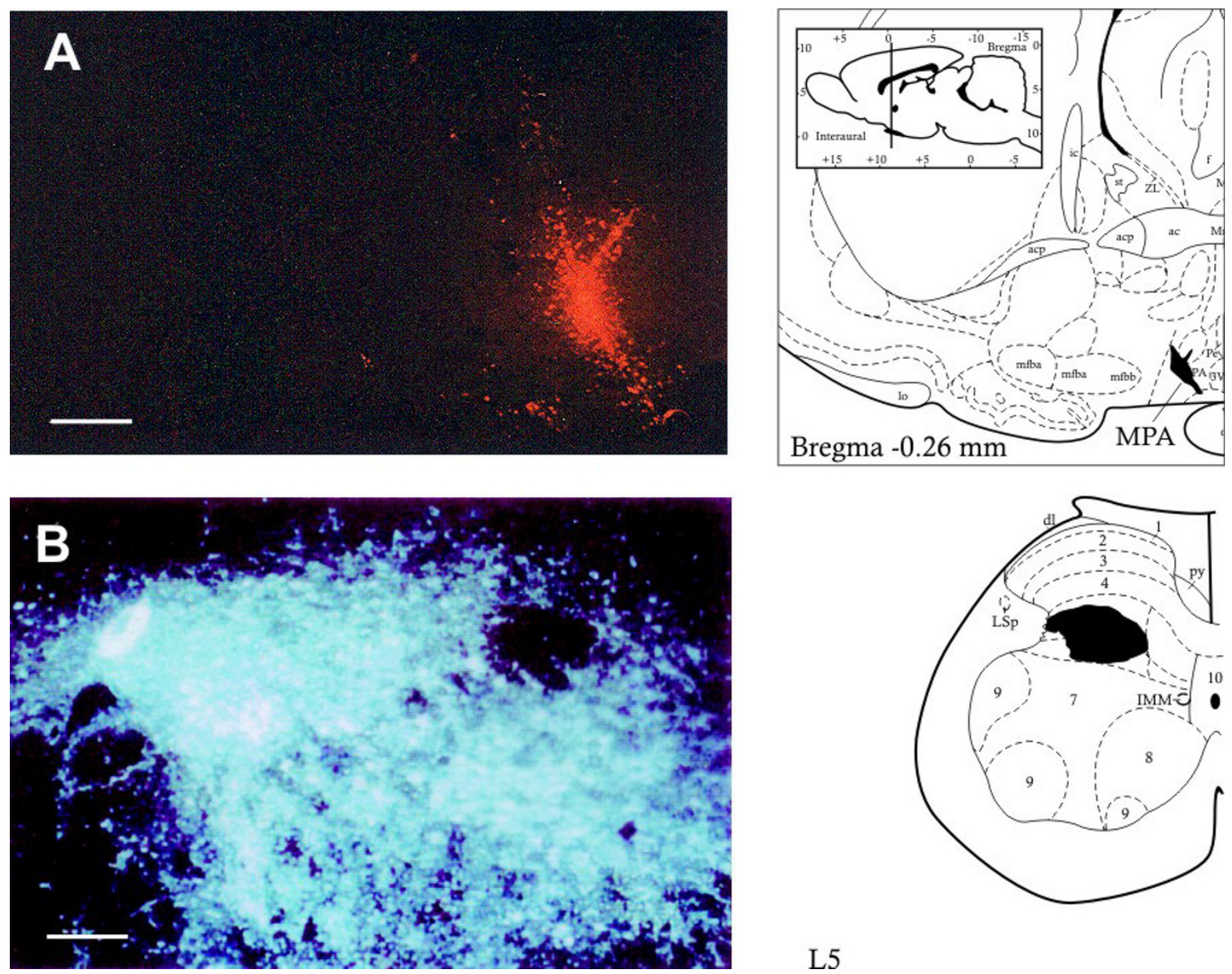

Figure I

Microphotographs show injection zones: in (A) RLB injection site and drawing in MPA (black area); Scale bar: $400 \mu \mathrm{m}$. In (B) FG injection site and drawing in SC-L (black area). Scale bar: $90 \mu \mathrm{m}$.

hypothalamic paraventricular nucleus [3], the lateral hypothalamic area [4], the dorsal raphe nucleus [5] and from other regions [4]. Some efferent RVL neurons project to the intermediolateral cell column of the thoraco-lumbar spinal cord and excite preganglionic sympathetic neurons [6-8], spinal phrenic motor neurons involved in inspiratory function [9] and increase the activity of vasoconstrictor fibres innervating blood vessels in the skin and skeletal muscle [10]. Ascending RVL efferent projections convey informations from RVL to diencephalic nuclei $[4,11]$ and collateralized fibres were found in RVL, after injections within the cerebellar fastigial nucleus and the superior colliculus [12]. In fact, electrical stimulation of RVL in rats elicits an excitatory response on the renal sym- pathetic nerve activity $[7,13]$. The MPA is also involved in controlling of numerous functions: neuroendocrine, sexual, maternal behaviour and other activities [14-16]. The aim of the present study is to demonstrate the existence of direct projections from RVL to the MPA and, via collaterals, the existence of direct projections to MPA and SC-L. In addition, previous work has shown that RVL adrenergic (C1) and non-adrenergic neurons were found to participate in these projections [17-19]. The brainstem neurons may be involved in simultaneous transmission of autonomic-related signals, in fact catecholaminergic and noncatecholaminergic neurons were found to provide branching collaterals to the central nucleus of the amygdala and to the hypothalamic paraventricular nucleus [11]. 


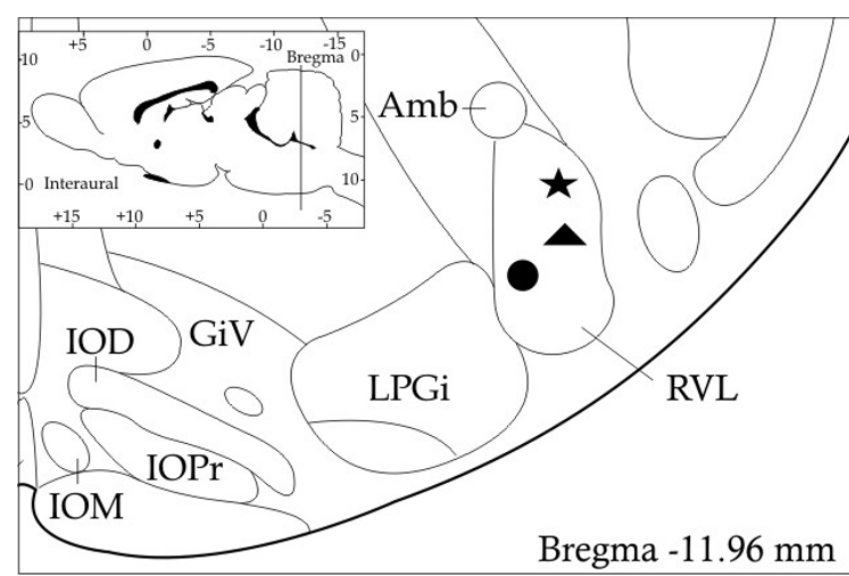

Figure 2

Schematic drawing atlas of frontal brain section including RVL region: circle indicates FG labelled neurons; triangle indicates RLB labelled neurons; star indicates FG-RLB labelled neurons.

In the present study we have used two retrograde tracers to determine the distribution of RVL neurons that project via collaterals to the MPA and SC-L.

\section{Results}

Only those cases (8 rats) where microscopic analysis of the injection sites revealed that the tracer deposits were correctly positioned were included in the study. Fig. 1 shows the injection sites of the retrograde tracers RLB in the MPA (A) and FG in the SC-L (B). The results showed a large number of retrogradely-labelled neurons in the whole ipsi- and contralateral RVL (stereotaxic planes: 11.60/-11.96). FG-labelled neurons from the ipsilateral and contralateral RVL were numerous (39.42 \pm 3.3$)$; moreover, these neurons ranged in size from medium $(20-30 \mu \mathrm{m})$ to large $(50 \mu \mathrm{m})$ and were rather sparse within RVL. RLB-labelled neurons were mostly packed within the boundaries of the field examined, consistently of medium size (20-35 $\mu \mathrm{m})$ and uniformly distributed in ipsi- and contralateral RVL $(38.2 \pm 2.85)$. The fluorescence microscopy revealed a substantial number of RVL doublelabelled neurons $(18.6 \pm 3.13)$, evidencing the presence of collateralization to the MPA and SC-L. These neurons generally were of medium to large size $(30-40 \mu \mathrm{m})$ and were localized in the middle third of RVL.

Fig. 2 shows schematic drawing of frontal brain section including RVL region with different symbol (circle, triangle and star) indicating the labelled neurons presence.
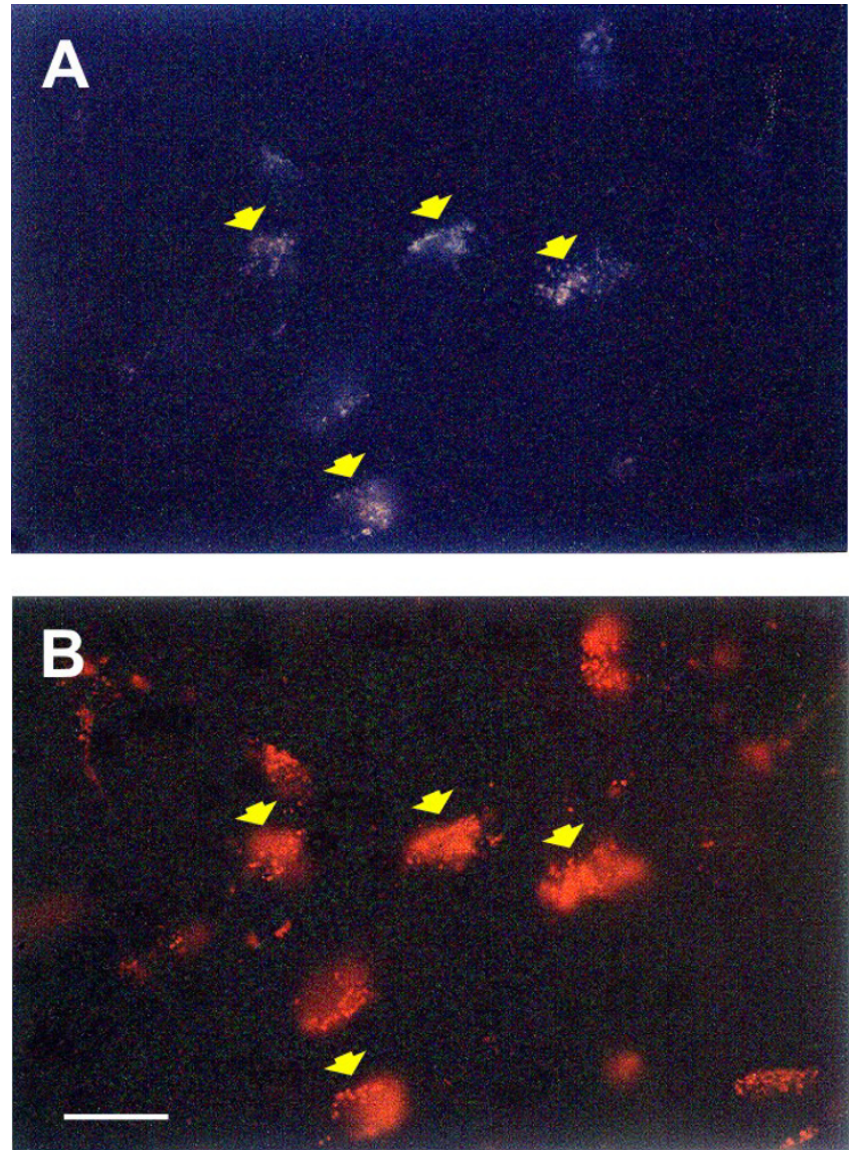

\section{Figure 3}

Microphotographs of double-labelled neurons FG-RLB in reticular ventrolateral nucleus (RVL). (A) cells stained positively to FG (excitation wavelength $330 \mathrm{~nm}$ ); (B) the same cells stained positively to RLB (excitation wavelength 560 $\mathrm{nm}$ ) indicating the existence of a collateral axon. Scale bar: 50 $\mu \mathrm{m}$.

A relatively low number of FG/RLB $(4.6 \pm 1.49$ neurons $)$ double-labelled neurons $(30-40 \mu \mathrm{m})$ were scattered mainly at the ipsilateral RVL level; an example is showed in Fig. 3.

\section{Discussion}

The present study provides direct evidence, based on retrograde tracing technique, that: 1) RVL single neurons directly project to the medial preoptic area; 2) RVL single neurons directly project to spinal cord, confirming previous results [4]; 3) RVL neurons supply, via collaterals, branching inputs to the MPA and SC-L. Sympatho-excitatory neurons of the RVL, like in rostral ventromedial medulla [20] and in caudal ventrolateral medulla [21], are important for the maintenance of tonic levels of arterial pressure they are intrinsic pacemaker activity and dis- 
charge continuously [2]. In conclusion, after the injections of FG and RLB, we show a cluster of branching RVL neurons in the rat brain. The fact that RVL contains neurons with a collateral fibers to both the spinal cord and to hypothalamic MPA, suggests that these neurons might play a role in maintaining activity of central and peripheral blood flow simultaneously.

\section{Materials and methods}

All experiments were carried out in accordance with current institutional guidelines for the care and use of experimental animals. Experiments were performed on 10 adult male Wistar rats weighing 250-300 g (Morini, Italy), maintained under controlled conditions of room temperature $\left(23 \pm 1^{\circ} \mathrm{C}\right)$ and lighting (lights on 07:00 19:00 h); laboratory chow diet and water were available ad libitum; the in vivo experimental procedure was performed during daytime (10:00 - 13:00 a.m.).

Animals were anaesthetized with chloral hydrate (400 $\mathrm{mg} / \mathrm{Kg}$, i.p.). Two fluorescent tracers were injected to the same rat: Fluoro Gold (FG) was injected into the lumbosacral spinal cord on one side, Rhodamine Labeled Bead (RLB) into the medial preoptic area of the same side. Rats were placed in a Kopf stereotaxic frame and injected with $0.08 \mu \mathrm{l}$ of undiluted RLB in the MPA, at the following coordinates $(0.30 ; \mathrm{L}=0.5 ; \mathrm{V}=-8.5)$ [22]; freshly dissolved FG $(0.15 \mu \mathrm{l}$ at $6 \%$ in saline) was injected into the SC-l. Both tracers were pressure-injected at a rate of $50 \mathrm{nl} / \mathrm{min}$. using $1 \mu \mathrm{l}$ Hamilton microsyringes.

Seven days after the injections, the animals were reanaesthetized and perfused through the ascending aorta with saline $(60 \mathrm{ml})$, followed by ice-cold $4 \%$ paraformaldehyde phosphate buffer ( $300 \mathrm{ml} ; \mathrm{pH} 7.4)$. The brains were removed, immersed in the same fixative for 3-4 $\mathrm{h}$ and cryoprotected overnight in phosphate-buffered with $20 \%$ sucrose solution.

Coronal sections $(40 \mu \mathrm{m})$ were cut on a cryostat (Reichert), mounted on slides and observed under fluorescent microscope (Polyvar Reichert) for identification of injection zones. The sections were air-dried, mounted and observed with a Reichert fluorescence microscope equipped with filter combinations revealing red (RLB), yellow (FG). For each animal, three non-adjacent sections were evaluated and the labelled cells plotted onto schematic drawings of the RVL region level (stereotaxic planes: -11.60 / -11.96) [5]. Thus, cell numbers were expressed as the average number/section calculated from these three sections.

\section{Competing interests}

The author(s) declare that they have no competing interests.

\section{Authors' contributions}

$\mathrm{AR}, \mathrm{RP}, \mathrm{RR}, \mathrm{SS}$ and $\mathrm{AJ}$ jointly conceived and executed this study and helped draft the manuscript. All authors read and approved the final manuscript.

\section{Acknowledgements}

We thank Mr. S. Bentivegna for helping with the photographic work. This study was supported by MIUR.

\section{References}

I. Aicher SA, Milner TA, Pickel VM, Reis DJ: Anatomical substrates for baroreflex sympathoinhibition in the rat. Brain Res Bull 2000, 5 I: :107-I10.

2. Reis DJ, Golanov EV, Ruggiero DA, Sun MK: Sympatho-excitatory neurons of the rostral ventrolateral medulla are oxygen sensors and essential elements in the tonic and reflex control of the systemic and cerebral circulations. J Hypertens 1994:S159-180.

3. Yang $\mathrm{Z}$, Coote $\mathrm{J}$ : Influence of the hypothalamic paraventricular nucleus on cardiovascular in the rostral ventrolateral medulla of the rat. J Physiol (Lond) 1998, 53 I:52 I-530.

4. Dampney RAL: Functional organization of central pathways regulating the cardiovascular system. Physiol Rev 1994, 74:323-364.

5. Underwood MD, Arango V, Bakalian MJ, Ruggiero DA, Mann JJ: Dorsal raphe nucleus serotonergic neurons innervate the rostral ventrolateral medulla in rat. Brain Res 1999, 824:45-55.

6. Minson JB, Arnolda LF, Llewellyn-Smith IJ: Neurochemistry of nerve fibers apposing sympathetic preganglionic neurons activated by sustained hypotension. J Comp Neurol 2002, 449:307-318.

7. Comer AM, Gibbons HM, Qi J, Kawai Y, Win J, Lipski J: Detenction of $\mathrm{mRNA}$ species in bulbospinal neurons isolated from the rostral ventrolateral medulla using single-cell RT-PCR. Brain Res Brain Res Prot 1999, 4:367-377.

8. Rajakumar N, Hrycyshyn AW, Flumerfelt BA: Afferent organization of the lateral reticular nucleus in the rat: an anterograde tracing study. Anat and Embryol (Berl) 1992, 185:25-37.

9. Sun MK, Reis DJ: Excitatory amino acid-mediated chemoreflex excitation of respiratory neurones in rostral ventrolateral medulla in rats. J Physiol 1996, 492:559-57I.

10. Dampney RAL, McAllen RM: Differential control of sympathetic fibres supplying hindlimb skin and muscle by subretrofacial neurones in the cat. J Physiol (Lond) 1998, 395:41-56.

I I. Petrov T, Krukoff TL, Jhamandas JH: Branching projections of catecholaminergic brainstem neurons to the paraventricular hypotalamic nucleus and the central nucleus of the amygdala in the rat. Brain Res 1993, 609:81-92.

12. Stanzani S, Russo A, Pellitteri R, Storaci G, Cataudella T: Branching projections of catecholaminergic ventrolateral reticular neurons to the fastigial nucleus and superior colliculus in the rat: triple labelling procedure. Neurosci Lett 200 I, 307:135-138.

13. Granata AR, Denavit-Saubie M: Bulbospinal sympathoexcitatory pathways in the rat. Brain Res Bull 1994, 34:60 I-605.

14. Ding YQ, Wang D, Jun-Qing X, Gong J: Direct projections from the medial preoptic area to spinally- projecting neurons in Barrington's nucleus: an electron microscope study in the rat. Neurosci Lett 1999, 27 I: I75-178.

15. Dominguez JM, Hul EM: Stimulation of the medial amygdala enhances medial preoptic dopamine release: implications for male rat sexual behavior. Brain Res 200I, 9 I 7:225-229.

16. Grattan DR, Rocca MS, Sagrillo CA, McCarthy MM, Selmanoff M: Antiandrogen microimplants into rostral medial preoptic area decrease gamma-aminobutyric acidergic neuronal activity and increase luteinizing hormone secretion in the intact male rat. Endocrinology 1996, I37:4167-4I73.

17. Aicher SA, Hahn B, Milner TA: N-methyl-D-aspartate-type glutamate receptors are found in post-synaptic targets of adrenergic terminals in the thoracic spinal cord. Brain Res 2000, 856: I-II.

18. Morrison SF, Callaway J, Milner TA, Reis DJ: Rostral ventrolateral medulla: a source of the glutamatergic innervation of the 
sympathetic intermediolateral nucleus. Brain Res 1991, 562: 126-135.

19. Sun MK, Young BS, Hackett JT, Guyenet PG: Rostral ventrolateral medullary neurons with intrinsic pacemaker properties are not catecholaminergic. Brain Res 1988, 45 I:345-349.

20. Babic T, Ciriello J: Medullary and spinal cord projections from cardiovascular responsive sites in the rostral ventromedial medulla. J Comp Neurol 2004, 469:391-4I 2.

21. Sun W, Panneton WM: Defining projections from the caudal pressor area of the caudal ventrolateral medulla. J Comp Neurol 2005, 482:273-93.

22. Paxinos G, Watson C: The rat brain in sterotaxis coordinates Academic Press: Sydney; 1986.

Publish with Bio Med Central and every scientist can read your work free of charge

"BioMed Central will be the most significant development for disseminating the results of biomedical research in our lifetime. "

Sir Paul Nurse, Cancer Research UK

Your research papers will be:

- available free of charge to the entire biomedical community

- peer reviewed and published immediately upon acceptance

- cited in PubMed and archived on PubMed Central

- yours - you keep the copyright

Submit your manuscript here:

http://www.biomedcentral.com/info/publishing_adv.asp 